\title{
Knowledge, attitudes, and practices among healthcare providers on cervical cancer, human papilloma virus and it's vaccine at ESI PGIMSR, MGM Hospital Parel Mumbai, India
}

\author{
Jaya K. Gedam, Disha A. Rajput*
}

Department of Obstetrics and Gynecology, ESIPGIMSR, Andheri, Mumbai, Maharashtra, India

Received: 11 August 2017

Accepted: 14 August 2017

*Correspondence:

Dr. Disha A. Rajput,

E-mail: disharajput@yahoo.co.in

Copyright: () the author(s), publisher and licensee Medip Academy. This is an open-access article distributed under the terms of the Creative Commons Attribution Non-Commercial License, which permits unrestricted non-commercial use, distribution, and reproduction in any medium, provided the original work is properly cited.

\begin{abstract}
Background: Cervical cancer is the second most common cause of cancer in females Worldwide and nearly $85 \%$ of the cervical cancer cases are diagnosed in developing countries. The health care providers can play an important role in promoting cervical cancer screening and knowledge about HPV vaccination. So this study was conducted to assess the knowledge, attitude and practices regarding cervical cancer screening and HPV vaccination and to analyze the factors influencing the knowledge about HPV vaccination, among nursing staff.

Methods: A cross-sectional study was conducted among 143 nurses and 75nursing students (total 218) at ESIPGIMSR MGM Hospital, Parel Mumbai. Data was collected using Questionnaire, designed based on the study objectives.

Results: $73(33.49 \%)$ of the nurses did received education on cervical cancer and HPV in the past. Most of the nurses, $184(84.4 \%)$ considered that they were at no risk of cervical cancer. $143(65.60 \%)$ nurses knew that Pap smear can be done to screen patients. Out of 141 married nurses, only 39 (27.28\%) regularly had a gynaecological examination and $105(74.47 \%)$ had never done Pap smear. In addition, $119(54.59 \%)$ participants did not know at what age Pap smear should commence. Only $73(33.49 \%)$ nurses knew about the route of transmission of HPV and $57(26.15 \%) \mathrm{knew}$ about HPV vaccine. 215 (98.62\%) nurses did not receive an HPV vaccine.

Conclusions: The nurses and nursing students did not have prior adequate education on cervical cancer, HPV, and vaccine and the desired level of knowledge on risk factors and signs of cervical cancer and prevention of the disease.
\end{abstract}

Keywords: Cervical cancer screening, HPV vaccine, Nursing staff, Pap smear

\section{INTRODUCTION}

Cervical cancer is the second most common cause of cancer in females worldwide. Out of which, nearly $85 \%$ of the cervical cancer cases are diagnosed in developing countries. ${ }^{1}$ In India, Cervical cancer is one of the most common causes of cancer among women. In 2010 approximately 74,000 new cases of cervical cancer were diagnosed in India. Out of these, 38\% Women were in the reproductive age group (15-49 years), indicates involvement of relatively younger population. In 1980, the mortality rate was 37 per 1000 new cases and in 2010, the morality rate was 32 per 1000 new cases, so there was hardly any improvement in two decades. ${ }^{2}$ In majority of cases, high mortality rates are because of late diagnosis of the disease or diagnosis at an advanced stage. According to a study nearly $70 \%$ of all cervical cancer cases in India are being diagnosed at an advanced stage (stage III or IV). ${ }^{3}$

Patients can be easily screened for cervical cancer by Pap smear or cytology. According to various reports, in 
developed countries $68-84 \%$ of women being screened by Pap smear, but in India this proportion is $2.6-5 \%$ only., This is one of the main reason that in India patients are being diagnosed at advanced stages. The main risk factor for development of Cervical cancer is infection with human papilloma virus (HPV) types (HPV 16 and HPV 18), which can be detected by cytology. ${ }^{1}$

Many clinical trials and systematic reviews all over the World, have shown the efficacy of vaccines 90-99\%, against HPV types (HPV 16 and 18), in preventing cervical intraepithelial neoplasia (CIN). The safety of these vaccines is also sufficiently established by these studies. ${ }^{6-8}$

In spite of knowledge about the association of HPV with cervical cancer and efficacy of HPV based screening and vaccination as an effective modes for primary prevention of carcinoma cervix, the attitude towards cervical cancer screening and HPV vaccines is very poor in many developing countries, including India. ${ }^{9}$ Various studies had concluded that lack of appropriate knowledge, negative attitude towards HPV vaccination and screening is one of the most important factor for poor acceptance of these services. ${ }^{10}$ Studies have also documented that the intention to refer patients for screening and HPV vaccination are dependent heavily on the knowledge and perceptions of the Health care providers. ${ }^{11}$

The health care providers can play an important role in promoting cervical cancer screening and knowledge about HPV vaccination. Lack of knowledge about cervical cancer among healthcare workers is a prime barrier for cervical cancer prevention.

Appropriate knowledge, positive attitude and high acceptance of these interventions among health care provider are very important for screening and HPV vaccination.

So, this study was conducted to assess the knowledge, attitude and practices regarding cervical cancer screening and HPV vaccination and to analyze the factors influencing the knowledge about HPV vaccination, among nursing staff.

\section{METHODS}

A cross-sectional, interview- based survey was conducted in ESI PGIMSR MGM Hospital, Parel in Mumbai, among nursing students (>18 years) and nurses working in the above-mentioned hospital who gave consent to be a part of study. An attempt was made to include all nursing students and staff nurses, hence no sampling was done. Nurses who were on long leave, or who declined to participate were excluded.

After getting approval from the institutional ethical committee, the purpose and nature of the study was explained to the subjects and written informed consent was obtained from all the subjects.

Out of 150 nursing staff 143 and out of 80 nursing students 75 participated in the study (total 218).

Data was collected using Questionnaire, designed based on the study objectives, taking help from the previous literature and studies available on the topic. The questionnaire was divided into 2 main parts, first dealing with the socio-demographic profile of the subjects (eg. age, education, obstetric history etc.) and second consisted of the questions regarding the knowledge, screening, risk factors, symptoms and signs of cervical cancer, and awareness about HPV vaccine and practices of nurses.

\section{Statistical analysis}

Data was analysed by Epi info 7 and descriptive statistics - frequencies and percentage were calculated.

\section{RESULTS}

Of the 230 (150 nurses +80 student nurses) at the institute $218(94.78 \%)$ participated in the study.

All the participants were females and 75 (34.40\%) of them were aged between 19-24 years, 94 (43.12\%) between 25-39 years and $49(22.48 \%)$ were $\geq 40$ years. Moreover, 10 (4.6\%) participants did high school, 65 (29.81\%) did 12th, 106 (48.62\%) did associate degree (nursing) and 37 (16.97\%) did B.Sc. nursing.

Besides, 80 (36.69\%) nurses had work experience of $<5$ years and $71(32.57 \%)$ had experience of 6-15 years. Furthermore, $141(64.68 \%)$ participants were married, 77 $(35.32 \%)$ had never been pregnant, $19(8.71 \%)$ had one child, $117(53.67 \%)$ gave live birth to two children and 5 $(2.29 \%)$ had 3 or $>$ children.

$73(33.49 \%)$ of the nurses reported that they received education on cervical cancer and HPV in the past. Most of the nurses, i.e. $184(84.4 \%)$ considered that they were at no risk of cervical cancer. Out of married nurses 20 $(14.18 \%)$ were not using any contraception (Table 1$)$.

Furthermore, $175(80.28 \%)$ of the nurses knew that cervical cancer is globally the second most frequent cancer in women. The most frequent four risk factors of cervical cancer described by the nurses were cigarette smoking 83 (38.07\%), unprotected sex 117 (53.67\%), multiparity $84(38.53 \%)$ and poor hygiene $149(68.35 \%)$ and the most frequent two symptoms of cervical cancer mentioned were post menopausal bleeding 103 (47.25\%) and foul smelling vaginal discharge 187 (85.78\%). The most common responses to the question, "What can be done to prevent cervical cancer?" were Pap smear test $143(65.60 \%)$, education $193(88.53 \%)$, and decreasing the number of deliveries 103 (47.25\%). In addition, 119 
(54.59\%) participants did not know at what age Pap smear tests should commence, while $15(6.88 \%)$ asserted that it should be performed in women who are sexually active for last three years. $174(79.82 \%)$ nurses knew that cervical biopsy can be done to detect $\mathrm{CaCx}$ and only 24 $(11.01 \%)$ were aware about visual inspection after acetic acid as screening method.

Table 1: Socio-demographic features of participants.

\begin{tabular}{|c|c|c|}
\hline Variables & n & $\%$ \\
\hline \multicolumn{3}{|l|}{ Age } \\
\hline $19-24$ & 75 & 34.40 \\
\hline $25-29$ & 25 & 11.47 \\
\hline $30-34$ & 32 & 14.68 \\
\hline $35-39$ & 37 & 16.97 \\
\hline$\geq 40$ & 49 & 22.48 \\
\hline \multicolumn{3}{|l|}{ Educational level } \\
\hline High school & 10 & 4.6 \\
\hline 12 th & 65 & 29.81 \\
\hline Associate degree (nursing) & 106 & 48.62 \\
\hline B.Sc. nursing & 37 & 16.97 \\
\hline \multicolumn{3}{|l|}{ Work experience } \\
\hline$<1$ year & 30 & 13.76 \\
\hline $1-5$ year & 50 & 22.93 \\
\hline $6-10$ year & 25 & 11.47 \\
\hline $11-15$ year & 46 & 21.10 \\
\hline$>15$ year & 67 & 30.73 \\
\hline \multicolumn{3}{|l|}{ Marital status } \\
\hline Unmarried & 77 & 35.32 \\
\hline Married & 141 & 64.68 \\
\hline \multicolumn{3}{|l|}{ No. of pregnancies } \\
\hline 0 & 77 & 35.32 \\
\hline 1 & 19 & 8.71 \\
\hline 2 & 117 & 53.67 \\
\hline$\geq 3$ & 5 & 2.29 \\
\hline \multicolumn{3}{|c|}{ Status of education on subject } \\
\hline No & 145 & 66.51 \\
\hline Yes & 73 & 33.49 \\
\hline \multicolumn{3}{|c|}{ Consider themselves in high risk group } \\
\hline No & 184 & 84.40 \\
\hline Yes & 34 & 15.60 \\
\hline \multicolumn{3}{|l|}{ Contraceptive use* } \\
\hline Natural & 7 & 4.96 \\
\hline Pills & 15 & 10.63 \\
\hline Injections & 3 & 2.13 \\
\hline Barrier & 26 & 18.43 \\
\hline IUCD & 45 & 31.91 \\
\hline Permanent & 25 & 17.73 \\
\hline None & 20 & 14.18 \\
\hline
\end{tabular}

The most commonly reported risk factors for HPV were unprotected sex $143(65.60 \%)$, multiple sexual partners $106(48.62 \%)$ and being sexually active from an early age $93(42.66 \%)$. Only $73(33.49 \%)$ nurses knew about the route of transmission of HPV and 57 (26.15\%) knew about HPV vaccine (Table 2).
Table 2: Knowledge of participants about cervical cancer (Ca Cx), HPV and its Vaccine.

\begin{tabular}{|c|c|c|}
\hline $\begin{array}{l}\text { Knowledge about } \mathrm{Ca} \text { Cx, HPV and its } \\
\text { Vaccine }\end{array}$ & n & $\%$ \\
\hline \multicolumn{3}{|c|}{$\begin{array}{l}\text { CaCx second most common cause of cancer in } \\
\text { females }\end{array}$} \\
\hline No & 43 & 19.72 \\
\hline Yes & 175 & 80.28 \\
\hline \multicolumn{3}{|l|}{ Risk factors for $\mathrm{CaCx}^{*}$} \\
\hline Cigarette smoking & 83 & 38.07 \\
\hline Multiple partners & 67 & 30.73 \\
\hline Early age at coitus & 63 & 28.90 \\
\hline Unprotected sex & 117 & 53.67 \\
\hline Multi parity & 84 & 38.53 \\
\hline Poor hygiene & 149 & 68.35 \\
\hline HPV infection & 73 & 33.49 \\
\hline \multicolumn{3}{|l|}{ Symptoms of $\mathrm{CaCx}^{*}$} \\
\hline Asymptomatic & 39 & 17.89 \\
\hline Post coital bleeding & 82 & 37.61 \\
\hline Post menopausal bleeding & 103 & 47.25 \\
\hline Intermenstrual bleeding & 84 & 38.53 \\
\hline Foul smelling vaginal discharge & 187 & 85.78 \\
\hline \multicolumn{3}{|l|}{ What can be done for prevention* } \\
\hline Pap smear test & 143 & 65.60 \\
\hline Pap can detect precancerous lesions & 85 & 38.99 \\
\hline Decrease no. Of pregnancy & 103 & 47.25 \\
\hline HPV vaccine & 29 & 13.30 \\
\hline Safe sex & 134 & 61.47 \\
\hline Barrier contraceptives & 84 & 38.53 \\
\hline Education & 193 & 88.53 \\
\hline Monogamy & 69 & 31.65 \\
\hline Prevent early age at pregnancy & 96 & 44.04 \\
\hline \multicolumn{3}{|l|}{ HPV risk factors } \\
\hline Early sex & 93 & 42.66 \\
\hline Early age at birth & 67 & 30.73 \\
\hline Cigarette smoking & 74 & 33.94 \\
\hline Polygamy & 106 & 48.62 \\
\hline Unprotected sex & 143 & 65.60 \\
\hline \multicolumn{3}{|l|}{ Know route of HPV transmission } \\
\hline Yes & 73 & 33.49 \\
\hline No & 145 & 66.51 \\
\hline
\end{tabular}

What age screening should commence for $\mathrm{CaCx}$

Did not know

Women $\geq 30$ year $\quad 119 \quad 54.59$

Women $\geq 21$ year who are $\quad 84 \quad 38.53$

sexually active for last 3 year $\quad 15 \quad 6.88$

Diagnostic modalities other than pap*

$\begin{array}{lll}\text { VIA** } & 24 & 11.01 \\ \text { Cervical biopsy } & 174 & 79.82 \\ \text { Colposcopy } & 54 & 24.77 \\ \text { Know about HPV vaccine } & & \\ \text { Yes } & 57 & 26.15 \\ \text { No } & 161 & 73.85\end{array}$

*Participants had more than one answer so total percentage may be more then 100, **Visual inspection after Acetic acid 
Out of 141 married staff nurses, only 39 (27.28\%) regularly had a gynaecological examination and 105 $(74.47 \%)$ had never done pap smear. $2(1.42 \%), 5$ (3.50\%), $16(11.34 \%), 13(9.22 \%)$ participants had a Pap smear test, annually and regularly, every 3-5 years, when they had any complaints and when a doctor advised respectively. When the reasons for not having a Pap smear were evaluated, $77(35.32 \%)$ stated that they were sexually inactive and among 141married participants who never did pap, the common responses were having inadequate knowledge $33(31.43 \%)$, not feeling at risk 25 (23.8\%) being shy about it $19(18.1 \%)$, no reason for a pap smear $17(16.19 \%)$ and lack of symptoms 11 $(10.48 \%)$ each. The reasons why they are not screening patients were, this is a doctor's job 181 (83.03\%), no indication $24(11.01 \%)$ and lack of vaginal speculum 13 (5.96\%). Also, $215(98.62 \%)$ nurses reported that they did not receive an HPV vaccine (Table 3 ).

Table 3: Practices and attitude of nursing staff about Cervical Cancer and HPV vaccine.

\begin{tabular}{|c|c|c|}
\hline Practices on $\mathrm{CaCx}$ and HPV & $\mathbf{n}$ & $\%$ \\
\hline \multicolumn{3}{|c|}{ Had regular gynaecological examination * } \\
\hline Yes & 39 & 27.28 \\
\hline No & 102 & 71.32 \\
\hline \multicolumn{3}{|l|}{ Having Pap smear test done* } \\
\hline Once a year & 2 & 1.42 \\
\hline Every 3-5 year & 5 & 3.50 \\
\hline When complaint & 16 & 11.34 \\
\hline When Doctor advised & 13 & 9.22 \\
\hline Never done & 105 & 74.47 \\
\hline \multicolumn{3}{|c|}{ Reason for not getting Pap smear done on self } \\
\hline No reason & 17 & 16.19 \\
\hline Not feeling at risk & 25 & 23.80 \\
\hline Being shy to have Pap smear & 19 & 18.10 \\
\hline Lack of symptoms & 11 & 10.48 \\
\hline Having inadequate knowledge & 33 & 31.43 \\
\hline \multicolumn{3}{|c|}{ Responses for not screening patients } \\
\hline No indication & 24 & 11.01 \\
\hline Lack of vaginal speculum & 13 & 5.96 \\
\hline It's doctor's job & 181 & 83.03 \\
\hline \multicolumn{3}{|l|}{ HPV vaccine received } \\
\hline Yes & 3 & 1.38 \\
\hline No & 215 & 98.62 \\
\hline
\end{tabular}

\section{DISCUSSION}

Cervical cancer is the second most common cause of cancer in females worldwide. Out of which, nearly $85 \%$ of the cervical cancer cases are diagnosed in developing countries. ${ }^{1}$ It has a very high mortality rate when not diagnosed in the early phase. ${ }^{3}$ Deaths due to cervical cancer, which are widespread in the community, can be reduced by increasing awareness among women. Knowledge of cervical cancer risk and education are very important in the diagnosis and treatment of the disease. In this respect, healthcare personnel, nurses in particular, have a burden of responsibility. This study was conducted to determine nurses' knowledge on this subject and status of nurses working and providing care to women at a hospital.

In present study majority of nurses $(80.28 \%)$ were aware that cervical cancer is among the most common cause of cancer in females but majority of the nurses $(66.51 \%)$ was found to have no prior education on cervical cancer, HPV or the vaccine. Knowledge of risk factors, signs and prevention methods of cervical cancer plays an important role in taking necessary precautions and avoiding behaviour deemed to be risky for cervical cancer.

Many participants $(65.60 \%)$ knew that pap smear can detect cervical cancer but only $38.99 \%$ participants were aware that it can detect precancerous lesions, which resembles with the two previous studies. ${ }^{12,13}$ Only $33.49 \%$ staff listed HPV as a risk factor despite many of them has listed unprotected sex as a risk factor. Many studies conducted in India had shown the association of HPV 16/18 with cervical cancer. ${ }^{14,15}$

Although knowledge is precursor of behaviour but attitude play an important role in formulating behaviour. ${ }^{16}$

In the present study, although the nurses considered Pap smear test as one of the most important practices in prevention of cervical cancer, the rate of having a Pap smear test was low. This suggested that the role of Pap smear test was underrated. In this study, a majority of the nurses $(71.32 \%)$ was found not to have regular gynaecological examinations and more than half of the nurses $(74.47 \%)$ have not done Pap smear screening previously. It is consistent with the studies which have indicated $74 \%$ in nurses and $86.8 \%$ in doctors, $86.7 \%$ in nurses did not go for pap smear. ${ }^{17,18}$ A study conducted among female doctors and nurses found out that only $13.9 \%$ of them had regular pap smear done. ${ }^{19}$ It is obvious that the number of women having Pap smear tests is very low, even among health care personnel.

Many authors have also suggested that HPV vaccine can reduce health and economic impact by reducing $\mathrm{CaCx}$ incidences. $^{14,20}$ But in present study $26.57 \%$ of participants knew about HPV vaccine and because of inadequate knowledge only $1.38 \%$ have received vaccine. One study reported that, $69.5 \%$ of the medical school students knew that HPV vaccine prevented approximately $70.0 \%$ of cervical cancers; however, only $13.9 \%$ of the students were found to receive at least one HPV vaccine. $^{21}$

The nurses' level of knowledge on the subject is a significant parameter when considering education of a society. A study reported that acceptance of the HPV vaccine in a society is affected by positive health policies motivating the use of the vaccine and they emphasised the role played by healthcare personnel in training 
programmes on HPV. ${ }^{22}$ The findings of the present study are comparable with the literature and have established insufficient knowledge of the nurses on HPV and its vaccine.

The current study has its limitations since its results cannot be generalised as it was conducted in a single hospital and the results of the study are limited to the period when data was collected.

In the light of the findings of the study, the nurses' level of knowledge on $\mathrm{CaCx}$, its risk factors, signs and prevention methods, Pap smear, and HPV and its vaccine should be increased, since healthcare personnel, in addition to the therapeutic services they provide, are responsible for providing preventive healthcare services and education and guidance for society.

\section{CONCLUSION}

The majority of the nurses and nursing students had no prior adequate education on cervical cancer, HPV, and vaccine and had inadequate knowledge and insufficient practical training on Pap smears. They did not have the desired level of knowledge on risk factors and signs of cervical cancer and prevention of the disease.

Funding: No funding sources

Conflict of interest: None declared

Ethical approval: The study was approved by the Institutional Ethics Committee

\section{REFERENCES}

1. Muñoz N, Bosch FX, de Sanjosé S, Herrero R, Castellsagué X, Shah KV et al. Epidemiologic classification of human papillomavirus types associated with cervical cancer. $\mathrm{N}$ Engl J Med. 2003;348:518-527.

2. Forouzanfar MH, Foreman KJ, Delossantos AM, Lozano R, Lopez AD, Murray CJ et al . Breast and cervical cancer in 187 countries between 1980 and 2010: a systematic analysis. Lancet. 2011;378:146184.

3. Vallikad E. Cervical cancer: the Indian perspective. FIGO 26th annual report on the results of treatment in gynecological cancer. Int $\mathrm{J}$ Gynecol Obstet. 2006;95:215-33.

4. Harry TK, Felicia MS, Ngugen S. A needs assessment of barriers to cervical cancer screening in Vietnamese American health care providers. Californian J Health Promotion. 2006;4:146-56.

5. Gakidou E, Nordhagen S, Obermeyer Z. Coverage of cervical cancer screening in 57 countries: low average levels and large inequalities. PloS Med. 2008;5:132.

6. Apter D, Wheeler CM, Paavonen J. Efficacy of human papillomavirus 16 and 18 (HPV-16/18) AS04-adjuvanted vaccine against cervical infection and precancer in young women: final event-driven analysis of the randomized, double-blind PATRICIA trial. Clin Vaccine Immunol. 2015;22:361-73.

7. Araujo SC, Caetano R, Braga JU, Costa e Silva FV. Efficacy of commercially available vaccines against HPV infection in women: a systematic review and meta-analysis. Cad Saude Publica. 2013;29:32-44.

8. Kumar S, Biswas M, Jose T. HPV vaccine: Current status and future directions. Med J Armed Forces India. 2015;71:171-7.

9. Raychaudhuri S, Mandal S. Socio-demographic and behavioural risk factors for cervical cancer and knowledge, attitude and practice in rural and urban areas of North Bengal, India. Asian Pac J Cancer Prev. 2012b;13:1093-6.

10. Aswathy S, Quereshi MA, Kurian B, Leelamoni K. Cervical cancer screening: Current knowledge and practice among women in a rural population of Kerala, India. Indian J Med Res. 2012;136: 205-10.

11. Riedesel JM, Rosenthal SL, Zimet GD, Bernstein DI, Huang B, Lan D et al. Attitudes about human papillomavirus vaccine among family physicians. J Pediatr Adolesc Gynecol. 2005;18:391-8.

12. Ertem G. Awareness of cervical cancer risk factors and screening behaviour among nurses in a rural region of Turkey. Asian Pac J Cancer Prev. 2009;10:735-8.

13. Singh E, Seth S, Rani V, Srivastava DK. Awareness of cervical cancer screening among nursing staff in a tertiary institution of rural India. J Gynecol Oncol. 2012;23:141-6.

14. Deodhar K, Gheit T, Vaccarella S, et al. Prevalence of human papillomavirus types in cervical lesions from women in rural Western India. J Med Virol. 2012;84:1054-60.

15. Basu P, Mittal S, Bhaumik S, Romao CC, Tenet V, Nene BM et al. Prevalence of high-risk human papillomavirus and cervical intraepithelial neoplasias in a previously unscreened population--a pooled analysis from three studies. Int J Cancer. 2013; 132: 1693-9.

16. Waller J, McCaffery K, Wardle J. Measuring cancer knowledge: comparing prompted and unprompted recall. Br J Psychol. 2004;95:219-34.

17. Yüksel KB, Sencan H, Kucur SK. The knowledge and tendency of doctors, nurses and hospital staff working in dumlupinar university - evliya celebi research and training hospital about human papilloma virus (HPV) infections and HPV vaccination. J Gyn Obst Neo. 2015;12:64-7

18. Yanikkerem E, Köker G. Knowledge, attitudes, practices and barriers towards hpv vaccination among nurses in Turkey: a longitudinal study. Asian APJCP. 2014;15:7693-702.

19. Kabacaoglu M, Oral B, Balci E, Gunay O. Breast and cervical cancer related practices of female doctors and nurses working at a university hospital in Turkey. APJCP. 2014;16:5869-73.

20. Armstrong EP. Prophylaxis of cervical cancer and related cervical disease: a review of the cost- 
effectiveness of vaccination against oncogenic HPV types. J Manag Care Pharm. 2010;16:217-30.

21. Maharajan MK, Rajiah K, Fang Num KS, Jin Yong N. Knowledge of human papillomavirus infection, cervical cancer and willingness to pay for cervical cancer vaccination among ethnically diverse medical students in Malaysia. APJCP. 2015;16:5733-9.

22. Jones M, Cook R. Intent to receive an HPV vaccine among university men and women and implications for vaccine administration. J Am Coll Health. 2008;57:23-32.

Cite this article as: Gedam JK, Rajput DA.

Knowledge, attitudes, and practices among healthcare providers on cervical cancer, human papilloma virus and it's vaccine at ESI PGIMSR, MGM Hospital Parel Mumbai, India. Int J Reprod Contracept Obstet Gynecol 2017;6:3855-60. 